\title{
Soil salinity prediction in the Lower Cheliff plain (Algeria) based on remote sensing and topographic feature analysis
}

\author{
Ibrahim YAHIAOUI ${ }^{1,2^{*}}$, Abdelkader DOUAOUI ${ }^{1,3}$, ZHANG Qiang ${ }^{4}$, Ahmed ZIANE ${ }^{1}$ \\ ${ }^{1}$ Laboratory of Crop Production \& Sustainable Valorization of Natural Resources, University Djilali Bounaama of Khemis Miliana, \\ Khemis Miliana 44225, Algeria; \\ ${ }^{2}$ Laboratory of Plant Ecology \& Environment, Biological Sciences Faculty, University of Sciences \& Technology Houari Boumediene, \\ Beb Ezzouar, Algiers 16111, Algeria; \\ ${ }^{3}$ University Center Morsli Abdellah, Tipaza 42000, Algeria; \\ ${ }^{4}$ Institute of Agricultural Environment and Resources, Shanxi Academy of Agricultural Sciences, Taiyuan 030006, China
}

\begin{abstract}
Soil salinity and ground surface morphology in the Lower Cheliff plain (Algeria) can directly or indirectly impact the stability of environments. Soil salinization in this area is a major pedological problem related to several natural factors, and the topography appears to be important in understanding the spatial distribution of soil salinity. In this study, we analyzed the relationship between topographic parameters and soil salinity, giving their role in understanding and estimating the spatial distribution of soil salinity in the Lower Cheliff plain. Two satellite images of Landsat 7 in winter and summer 2013 with reflectance values and the digital elevation model (DEM) were used. We derived the elevation and slope gradient values from the DEM corresponding to the sampling points in the field. We also calculated the vegetation and soil indices (i.e. NDVI (normalized difference vegetation index), RVI (ratio vegetation index), $\mathrm{Bl}$ (brightness index) and $\mathrm{Cl}$ (color index)) and soil salinity indices, and analyzed the correlations of soil salinity with topography parameters and the vegetation and soil indices. The results showed that soil salinity had no correlation with slope gradient, while it was significantly correlated with elevation when the EC (electrical conductivity) values were less than $8 \mathrm{dS} / \mathrm{m}$. Also, a good relationship between the spectral bands and measured soil EC was found, leading us to define a new salinity index, i.e. soil adjusted salinity index (SASI). SASI showed a significant correlation with elevation and measured soil EC values. Finally, we developed a multiple linear regression for soil salinity prediction based on elevation and SASI. With the prediction power of $45 \%$, this model is the first one developed for the study area for soil salinity prediction by the combination of remote sensing and topographic feature analysis.
\end{abstract}

Keywords: Landsat ETM+; morphology; sampling; salinity; prediction; Lower Cheliff plain

Citation: Ibrahim YAHIAOUI, Abdelkader DOUAOUI, ZHANG Qiang, Ahmed ZIANE. 2015. Soil salinity prediction in the Lower Cheliff plain (Algeria) based on remote sensing and topographic feature analysis. Journal of Arid Land, 7(6): 794-805. doi: 10.1007/s40333-015-0053-9

Remote sensing can provide a digital scan of any geographic surface on the Earth, especially when it is about the assessment of the ground surface patterns either in space or in time (Chen et al., 2009). Digital data are available for users nowadays and digital processing is the most accurate research tool in the field of environment (Metternicht and Zinck, 2003). Although the prediction of soil salinity obtained an important progress in the last decades and improved the understanding of spatial distribution of soil salinity, the accentuation of the occurrence of soil salinization under various factors and variables implied scientists to step forward in modeling this threat (Akramkhanov, 2005).

The assessment of soil salinity can be applied using digital indices extracted from satellite images with different spectral bands (Fernández-Buces et al., 2006; Farifteh et al., 2007). Digital elevation model (DEM)

*Corresponding author: Ibrahim YAHIAOUI (E-mail: ibyahiaoui@gmail.com)

Received 2015-01-21; revised 2015-03-21; accepted 2015-04-13

(C) Xinjiang Institute of Ecology and Geography, Chinese Academy of Sciences, Science Press and Springer-Verlag Berlin Heidelberg 2015 
can also be used to predict soil salinity following the variographic morphology of the ground surface with a perspective of improving the accuracy of its prediction (Browing and Duniway, 2011). The rapid spread of soil salinization is subjected mainly to the altitude above sea level, because the landforms control the transmission speed of salts across different soil layers (Mulder et al., 2011).

Remote sensing is proved to have advantages in predicting soil salinity. Meanwhile, the spatial distribution of soil salinity seems to be related to one or several variables, depending on the characteristics of the studied area (Boettinger et al., 2008; Allbed and Kumar, 2013). Researchers have developed many approaches to study and predict soil salinity with multiple variables using statistical analysis (Lesch et al., 1995; Eldeiry and Garcia, 2004). Multiple linear regression is proved to be one of the promising approaches in predicting and modeling soil salinity (e.g. Wang et al., 2007; Wang et al., 2013). Shrestha (2006) developed soil salinity prediction models using multiple linear regression based on remote sensing images and soil data in Thailand, while Mehrjardi et al. (2008) and Noroozi et al. (2012) proved the powerful use of multiple linear regression with Landsat TM and ETM+ spectral bands combined to the measured soil salinity data in Iran. Moreover, Bouaziz et al. (2011) used multiple linear regression with MODIS images and Allbed et al. (2014) used it with IKONOS spectral bands to assess soil salinity in the northern Brazil and in Al Hassa oasis in the eastern province of Saudi Arabia, respectively. Their findings of salinity prediction by integrating the digital data into a regression model allowed us to apply this statistical approach in our study area (the Lower Cheliff plain, Algeria), where soil salinization is serious for decades and is still a major environmental issue in the future.

The prediction of soil salinity in the Lower Cheliff plain is possible because Douaoui et al. (2006) provided the first soil salinity index in the area by using remote sensing images initially based on 3,980 soil samples. After that, Douaoui and Lepinard (2010) used a geostatistical approach based on Kriging methods to improve the accuracy of salinity digital mapping. From an ecological perspective, Mokhtari et al. (2012) used the previous results of soil salinity prediction to assess the influence of soil salinity on surface landscapes with ASTER image based on 400 soil samples. Generally, the use of very high-resolution (less than $2 \mathrm{~m}$ ) satellite images of Worldview-2 can improve the spatial prediction of soil salinity by creating a prediction index specific for the small region of H'madena, where an area of $10,000 \mathrm{hm}^{2}$ is classified as moderate to severe soil salinization (Douaoui and Yahiaoui, 2015).

The above-mentioned studies only focused on predicting soil salinity by using one variable (spectral reflectance) combined with the measured soil EC (electrical conductivity) data at a very limited scale in the study area. Thus, this study came up with a new perspective on the integration of new variables in soil salinity prediction, giving more significance and even more accuracy to the prediction of soil salinity in the Lower Cheliff plain with less soil samples (109). In this study, we developed a multiple regression approach for soil salinity prediction based on the digital data of Landsat ETM+ and the derived topography parameters (elevation, slope gradient, aspect and hillshade) that have already shown a very good individual correlation with measured soil salinity data in wet and dry seasons. This is the first research of considering terrain morphology as a variable in predicting soil salinity in the Lower Cheliff plain.

\section{Materials and methods}

\subsection{Study area}

The Lower Cheliff plain $\left(34^{\circ} 03^{\prime} 12^{\prime \prime}-35^{\circ} 05^{\prime} 57^{\prime \prime} \mathrm{N}\right.$, $00^{\circ} 40^{\prime} 00^{\prime \prime}-01^{\circ} 06^{\prime} 08^{\prime \prime} \mathrm{E}$; $11-185 \mathrm{~m}$ asl; Fig. 1 ), one of three plains in the great Cheliff Basin, is located in the Northwest Algeria. It has $60,000 \mathrm{hm}^{2}$ of area divided between farming lands to the east side of the plain and a saline patch (Sebkha), and bare dry lands to the west side (Douaoui et al., 2006). The Lower Cheliff plain is characterized by a semi-arid climate with high temperatures in summer and low in winter. The long dryness period ( 7 months of dry season) and low average annual precipitation (less than $250 \mathrm{~mm}$ ) in a year indicates that the area is situated in a climatic transition zone of semi-arid to arid climate (Yahiaoui and Douaoui, 2014). Soil salinization of the lower 


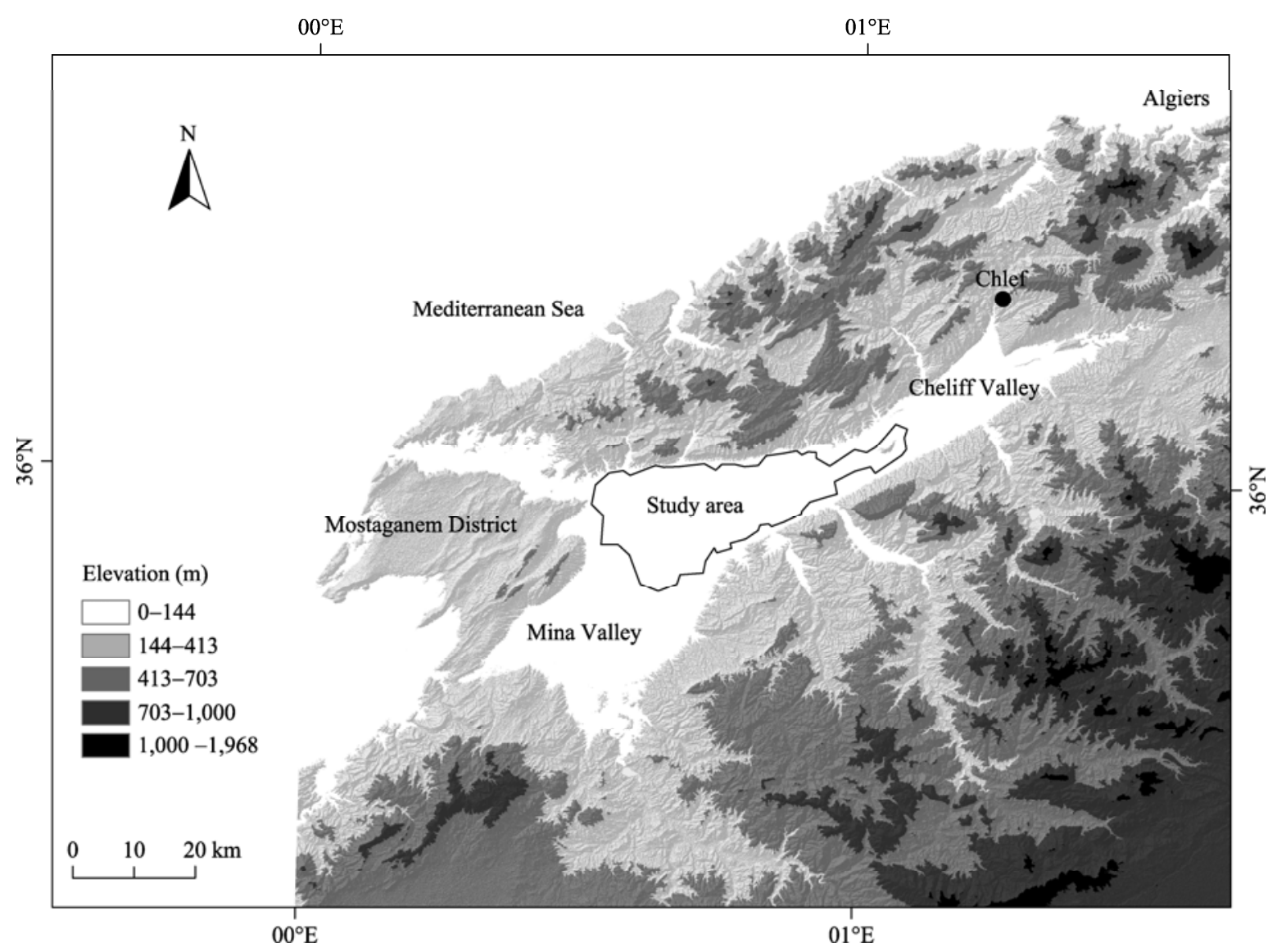

Fig. 1 Geographic location of the study area (the Lower Cheliff plain)

Cheliff plain can go back to the saliferous formations of Trias and Miocene, which are the original materials of alluvial plain coming from Ouarsenis, through the efflorescence of the Cheliff Valley. Soil salinization in the Lower Cheliff plain was accelerated in the last two decades following the increased utilization of groundwater to irrigation. Thus, soil salinization is the most serious problem that endangers the environment in the study area.

\subsection{Materials}

Two multispectral satellite images of Landsat ETM+ (http//:earthexplorer.usgs.gov) were used to predict soil salinity. The two satellite images included six spectral bands with the resolution of $30 \mathrm{~m}$ (Fig. 2). We also used a digital elevation model (DEM) of ASTER GDEM Version 2 with 30-m resolution in this study (Fig. 3). These three composites were processed using ENVI 4.8 and ArcGIS 9.3 softwares (ESRI tools). We selected two seasons (winter and summer) of 2013 based on the fact that the difference of soil salinity may be distinct under different underlying conditions especially vegetation cover. In this study, we compared the soil salinities in the winter and the summer to identify the season which had an obvious connection with the soil salinity.

The Lower Cheliff plain starts to extend on both sides from the bed of Cheliff River, by making junction with Oued Rhiou and Oued Djediouia on left bank and with the many streams coming from Dahra. On the right bank of Cheliff River, the plain extends until reaching the contributions of Mina Valley (Fig. 3). On the left bank of Cheliff River, the plain extends until it reaches a patch formed around the Sebkha (saline patch), where the slope increases gradually. In the middle of the plain, the slope of the ground is moderate and increases very slightly to the urban sites located at the piedmonts of Ouarsenis Mountains. The slope also varies on the right bank of Cheliff River in the same way. 

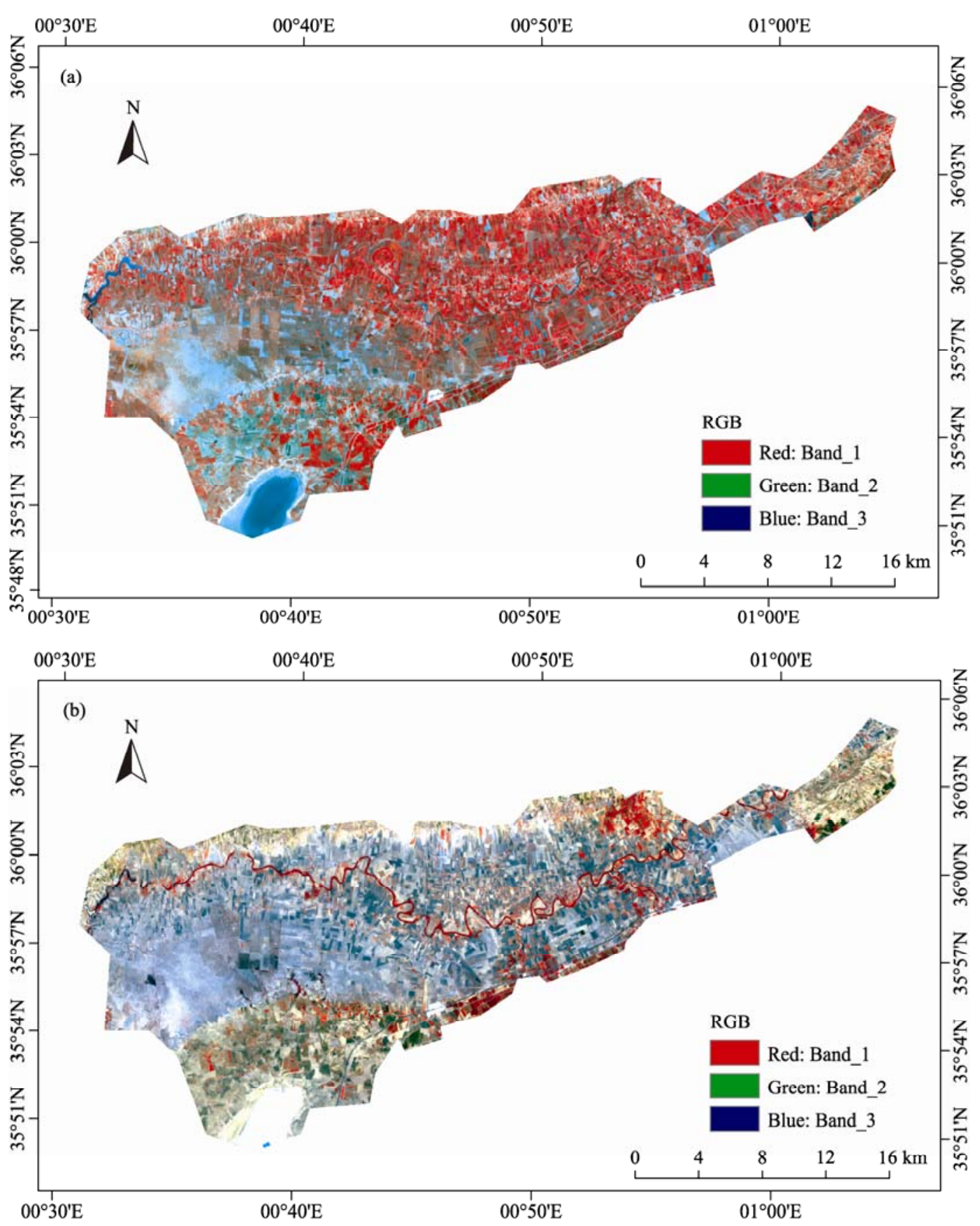

Fig. 2 Delimitation of the study area from Landsat scenes of (a) winter (February) and (b) summer (August) 2013

\subsection{Sampling scheme}

Soil sampling was performed in July 2012 with 109 points to measure soil EC. Following the gradient of soil salinity described by Douaoui and Lepinard (2010) and the ground surface morphology, we adopted a laminated sampling in the study area (Fig. 4). Soil samples were collected from the selected points during the dry season at the depth of $0-20 \mathrm{~cm}$, where salt accumulation was at high levels. Then, we measured soil EC in laboratory by using saturated paste method.

\subsection{Methods}

\subsubsection{Spectral reflectance}

The digital numbers of the pixels for each scene (winter and summer) were converted into reflectance values through atmospheric correction process on ENVI 4.8. We adopted the correction method specifically for 


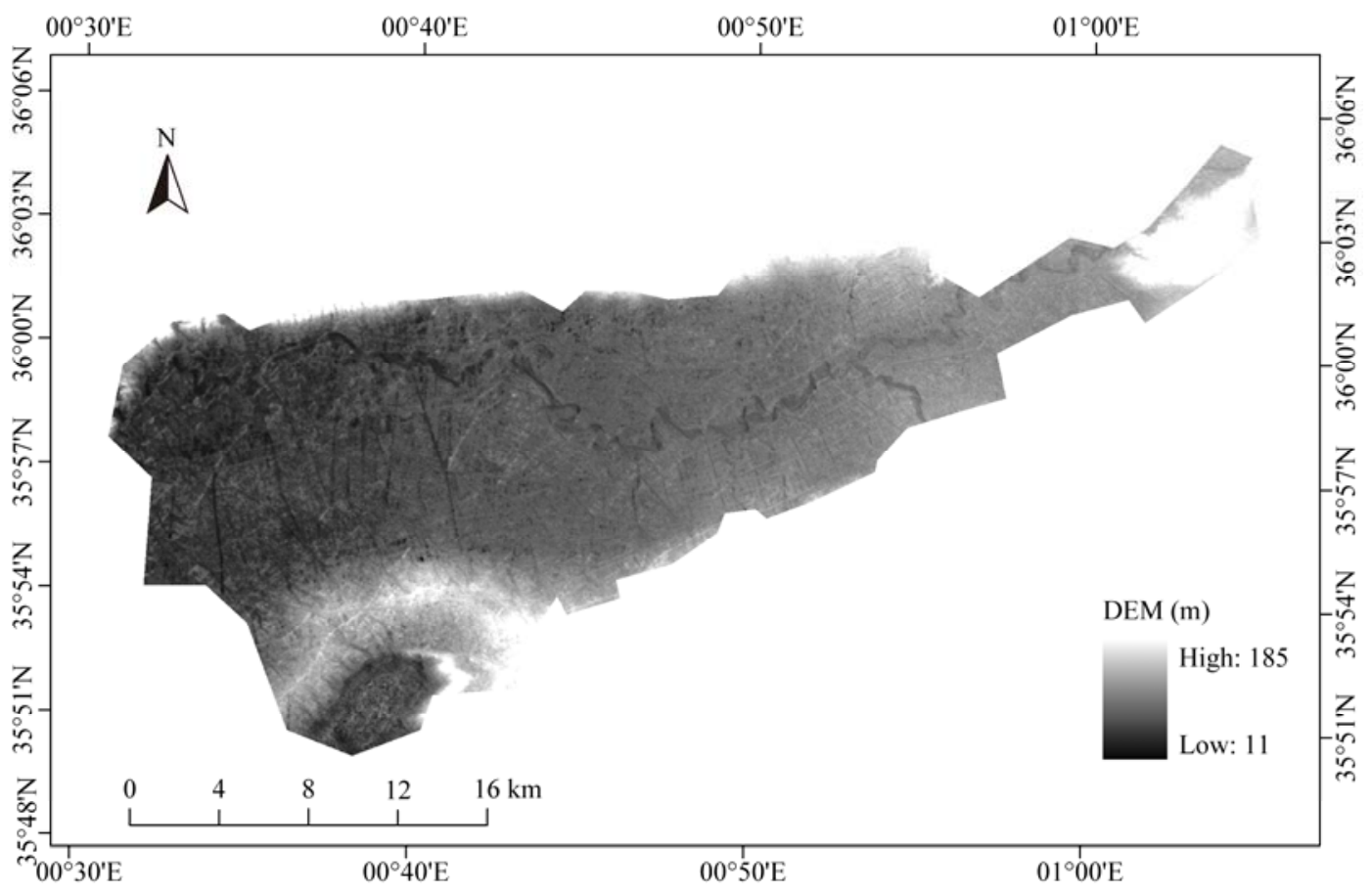

Fig. 3 Digital Elevation Model (DEM) of the study area (ASTER GDEM Version 2)

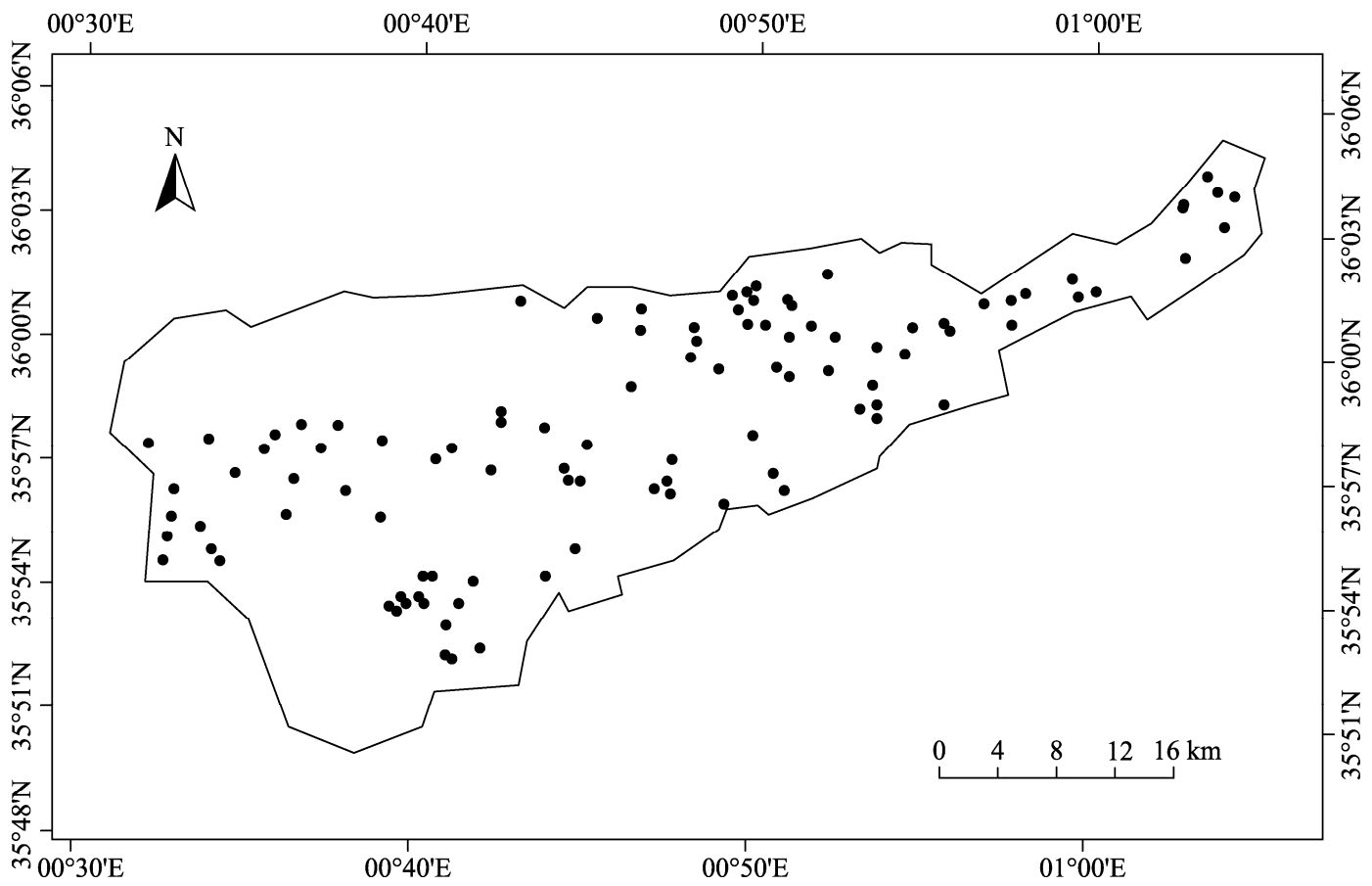

Fig. 4 Distribution of soil sampling points in the study area

Landsat TM and ETM+ proposed by Chander et al. (2009) and improved lately by Finn et al. (2012) to better fit a top of soil features extraction and to avoid the atmospheric noise during the extraction process.
This method was applied prior to the conversion process, i.e. the conversion of digital numbers of each band to radiance and then to reflectance values for both the summer and winter seasons. 
(1) Radiance

$$
\mathrm{L}_{\lambda}=\mathrm{G}_{\text {rescale }} \times \mathrm{DN}_{\lambda}+\mathrm{B}_{\text {rescale }} .
$$

Where, $\mathrm{L}_{\lambda}$ is the spectral radiance at the sensor's aperture $\left(\mathrm{W} /\left(\mathrm{m}^{2} \cdot \mathrm{sr} \cdot \mu \mathrm{m}\right)\right)$; $\mathrm{G}_{\text {rescale }}$ is the band specific rescaling gain factor $\left(\mathrm{W} /\left(\mathrm{m}^{2} \cdot \mathrm{sr} \cdot \mu \mathrm{m}\right)\right) ; \mathrm{DN}_{\lambda}$ is the digital number of the pixel on each band; and $\mathrm{B}_{\text {rescale }}$ is the band specific rescaling bias factor.

(2) Reflectance

$$
\rho=\frac{\pi \times \mathrm{L}_{\lambda} \times \mathrm{d}^{2}}{\mathrm{ESUN}_{\lambda} \times \sin [\pi \times(\mathrm{SE} \div 180)]} .
$$

Where, $\rho$ is the planetary TOA (Top of Atmospheric) reflectance (unitless); $\mathrm{L}_{\lambda}$ is the spectral radiance at the sensor's aperture; $d^{2}$ is the square of the Earth-Sun distance in astronomical units $((1-0.01674 \cos (0.9856$ $\left.(\mathrm{JD}-4)))^{2}\right)$; JD is the Julian Day (day number of the year) of the image acquisition; $\mathrm{ESUN}_{\lambda}$ is the mean solar exo-atmospheric irradiance $\left(\mathrm{W} /\left(\mathrm{m}^{2} \cdot \mathrm{mm}\right)\right)$; and $\mathrm{SE}$ is the sun elevation angle $\left(^{\circ}\right)$ when the scene was recorded.

\subsubsection{Indices}

(1) Soil salinity index (SSI)

Four soil salinity indices were selected in this study (Table 1). They are mainly used to detect soil salinity in an accurate way. The combination of spectral bands with these four indices can be applied to the Landsat scenes of the study area.

(2) Vegetation and soil indices

NDVI (normalized difference vegetation index), RVI (ratio vegetation index), BI (brightness index) and CI (color index) were used to express the vegetation and soil conditions, and to analyze the relationship between landscapes, ground surface morphology and soil salinity during the two seasons (Table 2). The selection of the two seasons returns to the expansion of the vegetation during the winter (February 2013) at the expense of soil due to the high amount of precipitation in this period (more than $100 \mathrm{~mm}$ ). Unlikely, soil reflectance of dry bare land in summer is more significant due to the big abstinence of vegetation.

\subsubsection{Extraction of topography parameters}

Using Spatial Analyst tool in ArcGIS software, we extracted the values of elevation $(\mathrm{Z})$, slope $(\mathrm{P})$, aspect (A) and hillshade (Hs) for each sampling points. We just presented the main parameters (elevation and slope gradient) in this study.

(1) Elevation

The Lower Cheliff plain has low to middle altitudes with a predominance in the depression of the far west (11-35 m), and some surfaces to the mid-west (35-50 $\mathrm{m})$, and east and mid-east (50-60 m). However, in the east of the plain and on its peripheries, the elevation increases to $140 \mathrm{~m}$ (Fig. 5). Elevation in the down west side varies between 70-120 m. In general, elevation is low in the western part of the plain and increases towards the east.

(2) Slope gradient

The slope gradient in the Lower Cheliff plain varies in

Table 1 Description of soil salinity indices used in this study

\begin{tabular}{ccc}
\hline Soil salinity index & Equation & Reference \\
\hline SSI 1 & $(G \times R)^{1 / 2}$ & Khan et al. (2001) \\
SSI 2 & $2 \times G-(R+N I R)$ & Douaoui and Lepinard (2010) \\
SSI 3 & $\left(R^{2}+G^{2}\right)^{1 / 2}$ & Douaoui et al. (2006) \\
SSI 4 & $(R-N I R) /(R+N I R)$ & Dehni and Lounis (2012) \\
\hline
\end{tabular}

Note: SSI, soil salinity index. G, R and NIR represent spectral bands for green, red and near infrared, respectively.

Table 2 Description of vegetation and soil indices used in this study

\begin{tabular}{ccc}
\hline Index & Equation & Reference \\
\hline NDVI & $(N I R-R) /(N I R+R)$ & Rouse et al. (1974) \\
RVI & $N I R / R$ & Pearson and Miller (1972) \\
BI & $\left(G^{2}+R^{2}+N I R^{2}\right)^{1 / 2}$ & Manière et al. (1993) \\
CI & $(R-G) /(R+G)$ & Huete et al. (1994) \\
\hline
\end{tabular}

Note: NDVI, normalized difference vegetation index; RVI, ratio vegetation index; BI, brightness index; CI, color index. 
a range from 0 to almost 20\% (Fig. 6). The lower values $(0-2 \%)$ are found in the far west, with slight increases toward the peripheries of western and eastern parts $(6 \%$ to $7 \%)$ in the form of low lands. The slope values in the down, up west and mid-east of the plain vary from $9 \%$ to $12 \%$. The slopes of hill in the far east of the plain exceed $20 \%$.

1.4.4 Statistical analysis

First, we analyzed the relationship of measured soil EC with the extracted topography parameters using

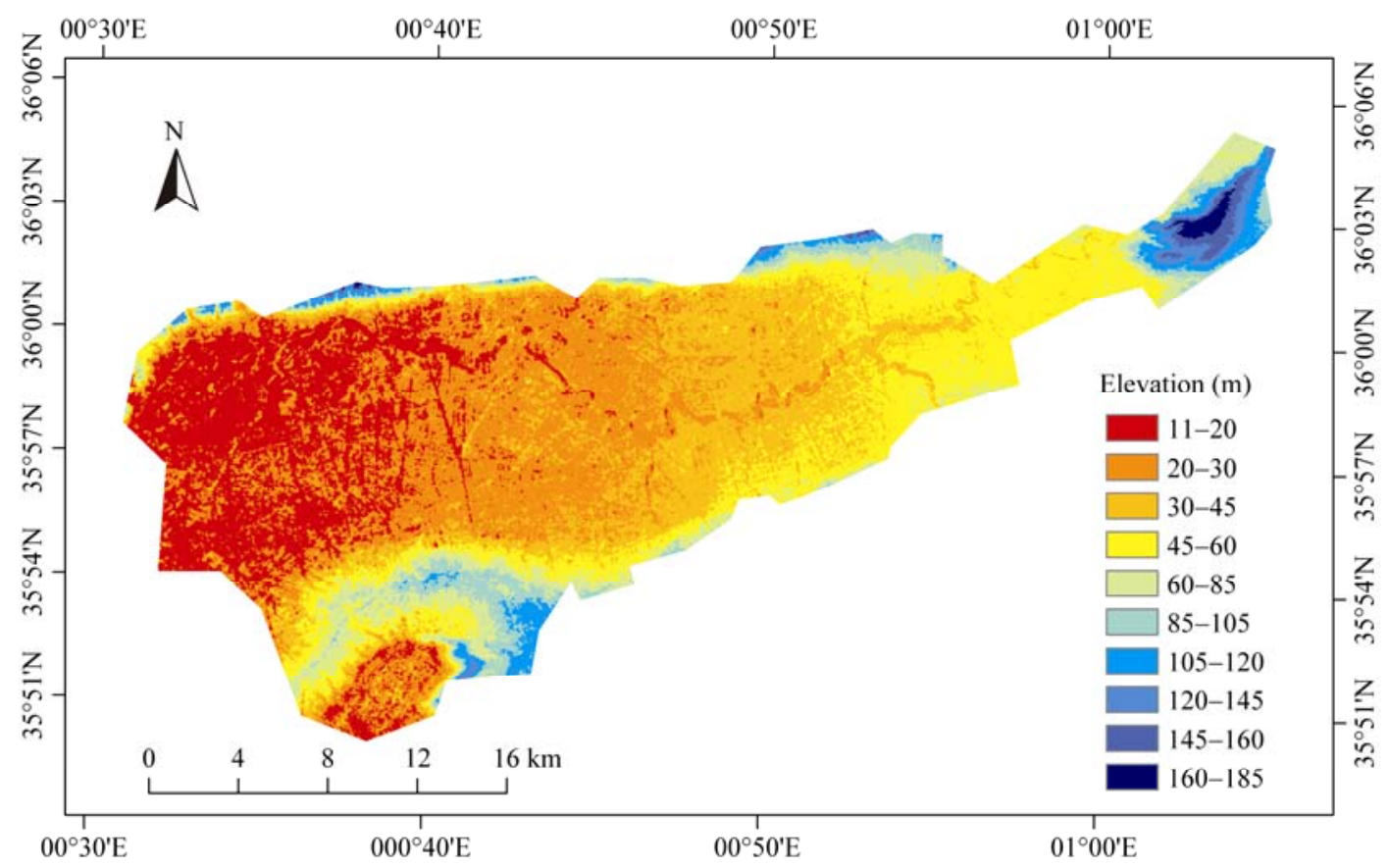

Fig. 5 Elevation distribution in the study area derived from the digital elevation model (DEM)

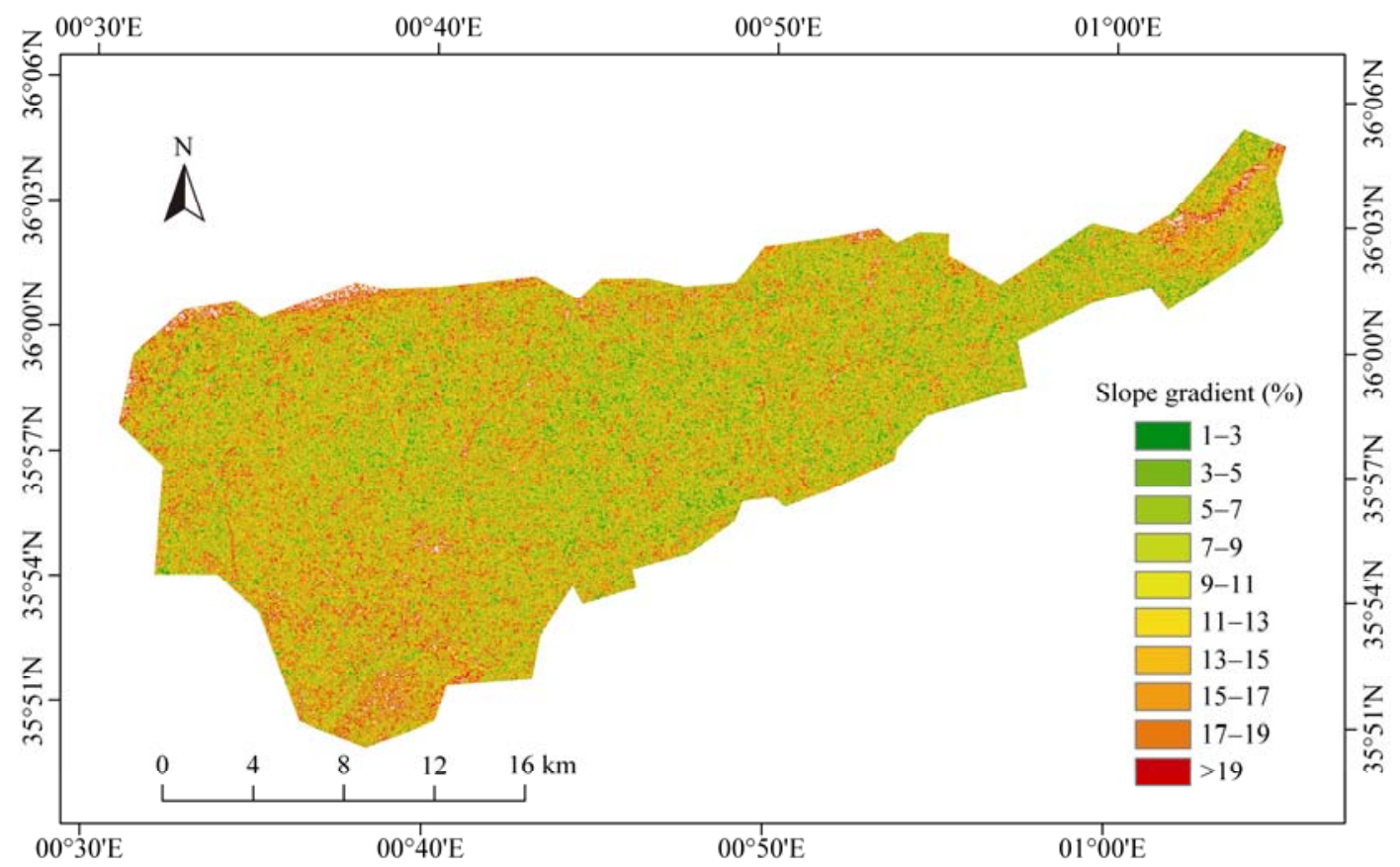

Fig. 6 Slope gradient in the study area derived from the digital elevation model (DEM) 
Pearson correlation analysis. Next, we combined the soil EC data with the calculated vegetation and soil indices, also, with the reflectance values for the two seasons (winter and summer) to determine which season shows a better correlation with soil salinity.

Finally, we used stepwise multiple regression in XLSTAT 2012 software to determine the efficiency of the selected variables in explaining the dependent variable EC. Once the model was established, we applied a validation based on: (1) the coefficient of determination $R^{2}$, representing a good linear relationship; (2) low RMSE (root mean square error) for the established model; and (3) significance levels of $P<0.05$ and $P<0.001$, and low standard errors for the used variables in the model.

\section{Results and discussions}

\subsection{Relationship between measured soil EC and Landsat data}

For both seasons, measured soil EC had weak correlations with soil and vegetation indices (Table 3), indicating the weak response of these indices to soil salinity (Fernández-Buces et al., 2006). Moreover, SSI 2 and SSI 3 were significantly negatively correlated with soil salinity in winter, and soil salinity presented a sharp decrease under the effect of soil leaching by precipitation during this period (Khan et al., 2001). The important difference in the correlation of measured soil salinity and these indices between the two seasons returned essentially to the double effect of the climate and soil salinity. In winter, precipitations wash the salts from surface and subsurface soils, and allow the vegetation to grow and extend spatially (Yahiaoui and Douaoui, 2014). During summer, due to the absence of rainfalls, the return of soil salts back near the surface are behind the abstinence of vegetation, resulting in an obvious extent of bare dry lands with saline soils (Mokhtari et al., 2012).

\subsection{Relationship between measured soil EC and topography parameters}

2.2.1 Relationship of measured soil EC with slope gradient, aspect and hillshade

The correlations of soil salinity with the extracted topography parameters (aspect, hillshade and slope) appeared to be low for the aspect $\left(R^{2}=0.0016\right)$ and hillshade $\left(R^{2}=0.0004\right)$, and very low for the slope $\left(R^{2}=\right.$ 0.0001 ; Fig. 7). Although the soil samples were selected from a topographical perspective, these topographical variables still showed low correlations with measured soil salinity in the area, mainly because of their low variability in the study area (Mulder et al., 2011). The study area is a plain and its topography changes very little.

\subsubsection{Relationship between measured soil EC and elevation}

Elevation showed a significant relationship with measured soil salinity in an opposite tendency $\left(R^{2}=\right.$ 0.4497; Fig. 8a). The coefficient rose to be 0.6235 when the correlation becomes exponential (Fig. 8b), maintaining the condition that soil salinity decreased with the increase of elevation (Boettinger et al., 2008). The selection of the best fits of measured soil EC values to elevation restricted the EC values to less than 8 $\mathrm{dS} / \mathrm{m}$, and the coefficient of linear correlation between soil $\mathrm{EC}<8 \mathrm{dS} / \mathrm{m}$ and elevation increased $\left(R^{2}=0.7182\right.$;

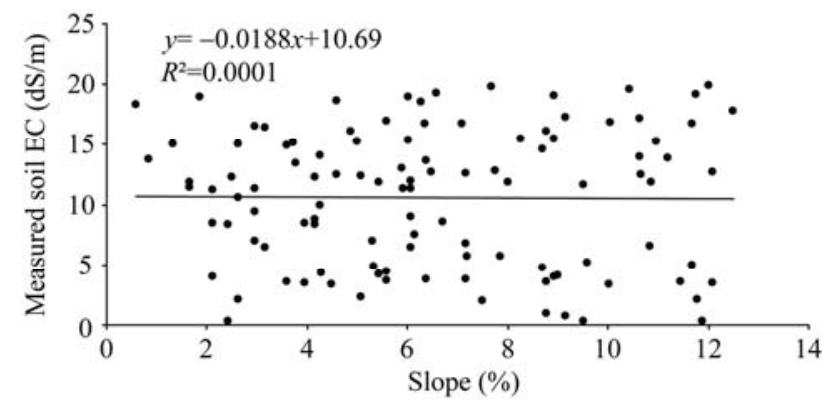

Fig. 7 Relationship between measured soil EC and slope

Table 3 Correlation matrix of measured soil EC with soil and vegetation indices and soil salinity indices for the two seasons

\begin{tabular}{ccccccccc}
\hline & BI & CI & NDVI & RVI & SSI 1 & SSI 2 & SSI 3 & SSI 4 \\
\hline Winter & -0.04 & 0.03 & -0.36 & -0.34 & -0.24 & $-0.38^{* * *}$ & $-0.40^{* * *}$ & -0.21 \\
Summer & 0.06 & -0.08 & -0.28 & -0.25 & 0.20 & $0.22^{* * *}$ & $0.24^{* * *}$ & 0.18 \\
\hline Note: ${ }^{* * *}$ means significance at & $P<0.001$ level. & & & & & &
\end{tabular}

Note: ${ }^{* * *}$ means significance at $P<0.001$ level. 

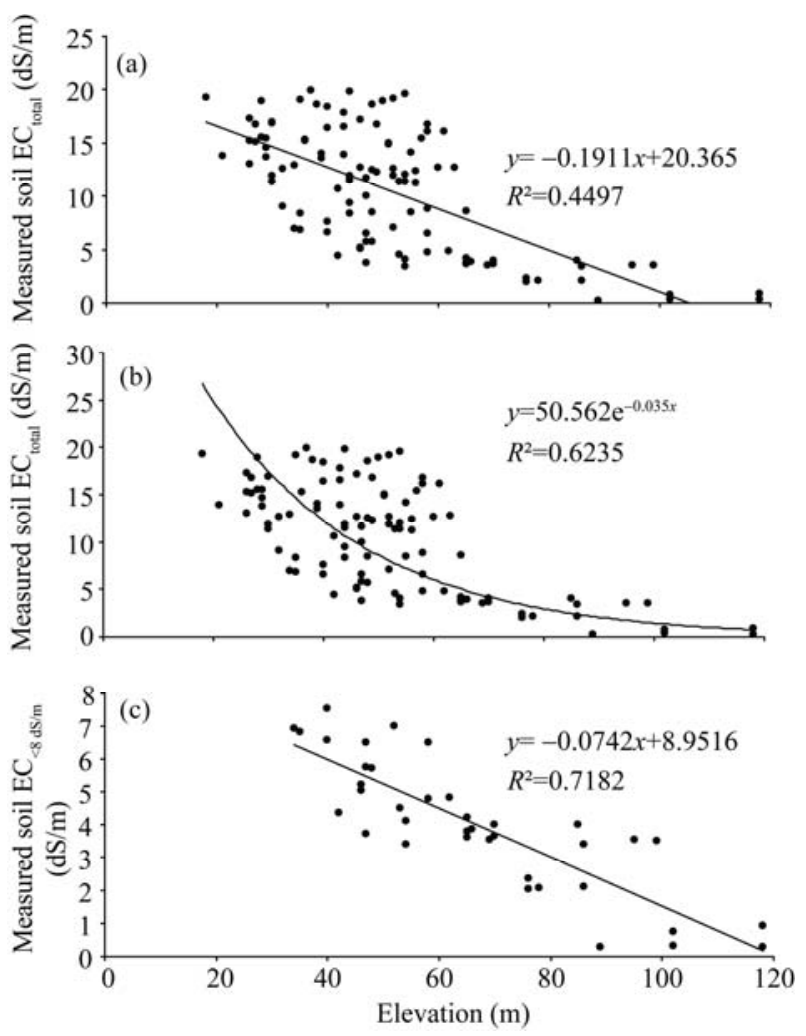

Fig. 8 Linear correlation between measured soil $E_{C_{\text {total }}}$ and elevation (a), exponential correlation between measured soil $\mathrm{EC}_{\text {total }}$ and elevation (b), and linear correlation between measured

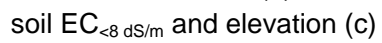

Fig. 8c), indicating that elevation is a good predictor of soil salinity using well selected digital data of topography.

\subsection{Relationship of topography with soil and veg- etation indices and soil salinity indices}

We analyzed the relationships of topography parameters with soil and vegetation indices and soil salinity indices. Non-significant correlation was found between the aspect, hillshade and these indices $\left(R^{2}<0.001\right)$. The slope values showed a very low correlation with soil and vegetation indices during winter and summer (Table 4). Slope was only significantly negatively correlated with SSI 2 in summer, indicat- ing the weak relationship between the slope and underlying conditions as well as soil salinity in the study area.

The relationship of elevation with soil and vegetation indices showed that the correlation was more significant for summer than for winter even with low coefficients (Table 5). The correlation coefficients were higher for summer (dry season), due to the improved underlying conditions during this period through spectral reflectance (Boettinger et al., 2008).

\subsection{Soil adjusted salinity index (SASI)}

The visible spectral bands B1, B2 and B3 showed significant correlations with measured soil EC among the six selected spectral bands for both seasons (Table $6)$. The correlation coefficients were higher for summer, indicating that soil salinity can be predicted better through reflectance data during the dry season (Al-Khaier, 2003).

For the two seasons, the correlation coefficient between measured soil EC and B3 was the highest, followed by B2. Hence, the new equation of soil adjusted salinity index (SASI) can be defined as follows:

$$
\mathrm{SASI}=\frac{\mathrm{R}}{100 \times \mathrm{B}^{2}}
$$

Where, $\mathrm{R}$ is the red band and $\mathrm{B}$ is the blue band. This new index showed a significant correlation with elevation $\left(R^{2}=0.5929\right)$ and soil salinity during summer $\left(R^{2}=0.3844\right)$. In addition to elevation, SASI is also a variable in predicting soil salinity.

\subsection{Development of regression model for soil sa- linity prediction}

We developed a multiple linear regression model for soil salinity prediction depending on the good correlation of soil EC with elevation and the new established index (i.e. SASI). The statistical results showed the significance of the developed regression model in predicting soil salinity, with $99 \%$ confidence level for elevation and $97 \%$ confidence level for SASI.

Table 4 Correlation matrix of slope with soil and vegetation indices and soil salinity indices for the two seasons

\begin{tabular}{cccccccccccc}
\hline & BI & CI & NDVI & RVI & SSI 1 & SSI 2 & SSI 3 & SSI 4 \\
\hline Winter & -0.13 & 0.09 & -0.05 & -0.09 & 0.04 & 0.04 & -0.05 & 0.02 \\
Summer & 0.16 & 0.04 & 0.04 & 0.02 & 0.08 & $-0.21^{* * *}$ & 0.09 & -0.02 \\
\hline
\end{tabular}

Note: ${ }^{* * *}$ means significance at $P<0.001$ level. 
Table 5 Correlation matrix of elevation with soil and vegetation indices and soil salinity indices for the two seasons

\begin{tabular}{ccccccccccc}
\hline & BI & CI & NDVI & RVI & SI 1 & SI 2 & SI 3 & $-0.41^{* * *}$ & $-0.42^{* * *}$ & -0.16 \\
Winter & -0.04 & -0.02 & 0.13 & 0.11 & -0.39 & -0.30 & $-0.37^{* * *}$ & $-0.39^{* * *}$ & -0.14 \\
\hline Summer & 0.22 & 0.17 & 0.26 & 0.20 & -0.14
\end{tabular}

Note: ${ }^{* * *}$ means significance at $P<0.001$ level.

Table 6 Correlation matrix of measured soil EC with six spectral bands and elevation for the two seasons

\begin{tabular}{ccccccccc}
\hline & B1 & B2 & B3 & B4 & B5 & B6 & Elevation \\
\hline Winter & $-0.31^{* * *}$ & $-0.27^{* * *}$ & $-0.32^{* * *}$ & 0.03 & 0.02 & 0.01 & $-0.67^{* * *}$ \\
Summer & $-0.47^{* * *}$ & $-0.31^{* * *}$ & $-0.52^{* * *}$ & -0.15 & 0.19 & -0.12 & $-0.67^{* * *}$ \\
\hline
\end{tabular}

Note: ${ }^{* * *}$ means significance at $P<0.001$ level. B1, blue band (B); B2, green band (G); B3, red band (R); B4, near infrared (NIR); B5, short wave infrared 1 (SWIR1); B6, short wave infrared 2 (SWIR2).

However, the prediction power is only $45 \%$ due to the moderate spatial resolution $(30 \mathrm{~m})$ either for the satellite imagery (Tajgardan et al., 2010) or the DEM. The good linear correlations of measured soil EC with elevation and SASI $\left(R^{2}=0.4489\right.$ and $R^{2}=0.3844$, respectively) showed that soil salinity can be predicted possibly using more than one variable. Therefore, the multiple linear regression for soil salinity prediction in this study can be expressed as Eq. 4.

$$
\mathrm{EC}=31.442-0.136 \times \mathrm{Z}-0.113 \times \mathrm{SASI} \text {. }
$$

Where, $\mathrm{Z}$ is the elevation $(\mathrm{m})$, and SASI is the soil adjusted salinity index.

We developed the multiple linear regression on the best fit of the variables to regression selection criteria, the good relationship $\left(R^{2}=0.4558\right)$ at $97 \%$ of probability and RMSE of $4.21 \mathrm{dS} / \mathrm{m}$ (Fig. 9). A small standard error for each variable from the model also indicated the efficiency of the developed model (Wang et al.,
2007; Wang et al., 2013). The use of Kriging approach in estimating soil salinity proved its efficiency in reducing the prediction error (Douaoui and Yahiaoui, 2015). The low RMSE in our model is due to the soil samples were selected with $\mathrm{EC}<20 \mathrm{dS} / \mathrm{m}$. It can be even decreased with the increasing number of EC data. The establishment of this prediction model is possible because the red and blue bands are the main visible bands in retrieving soil salinity (Mehrjardi et al., 2008; Noroozi et al., 2012) through different seasons. According to the study of Akramkhanov (2005), ground surface morphology has a remarkable influence on soil salinity in the surface soil layer. Salinity prediction using terrain elevation appears to be better in dry period. Although surface reflectance is higher in this period, the spatial variation of EC values can be easily detected (Boettinger et al., 2008). This is consistent to what Eldeiry and Garcia (2004), Srestha (2006) and

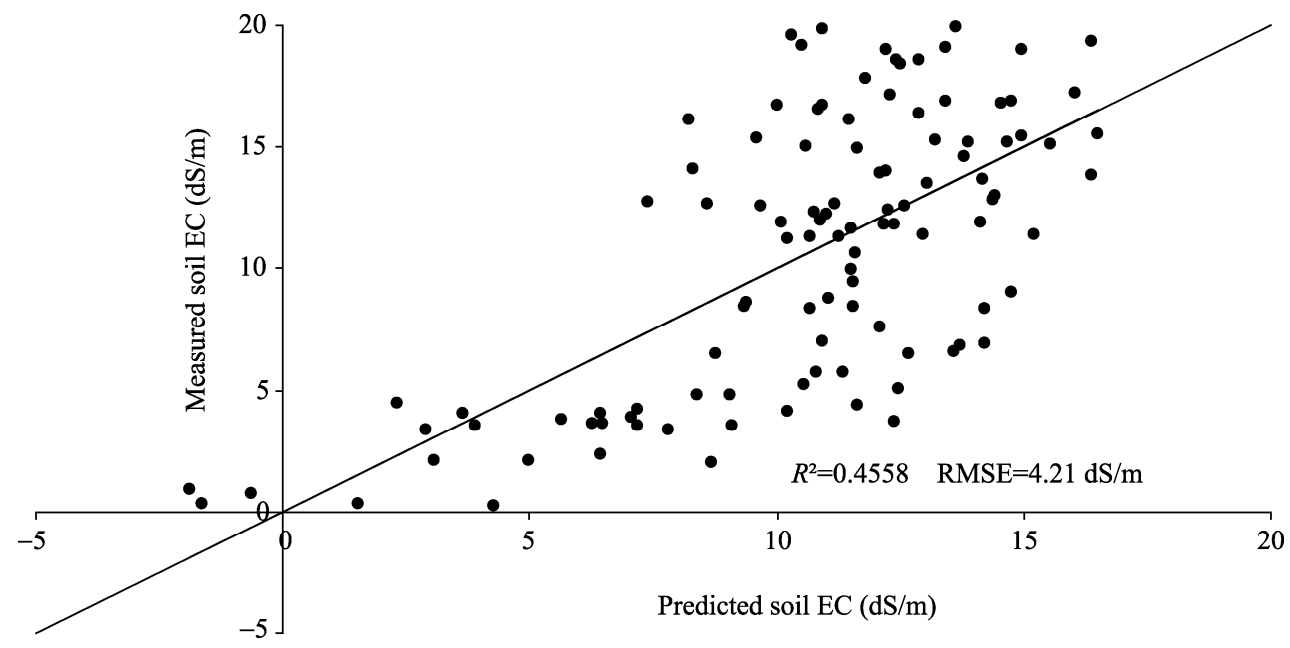

Fig. 9 Scatter plot of the predicted and measured soil EC for the developed multiple linear regression 
Bouaziz et al. (2011) found by combining spectral bands with enhanced images in a single model. In addition, the prediction model can be applied under the limitation of multispectral data in terms of spectral and spatial resolution (Albed et al., 2014).

\section{Conclusions}

This study aimed to improve the predictive accuracy of soil salinity in the Lower Cheliff plain by integrating the remote sensing images and topography parameters which showed interesting statistical relationship with measured soil salinity on the basis of less soil samples. Analysis of the relationship between measured soil salinity and extracted topography parameters showed that soil EC was only significantly correlated with elevation, while it had no correlation with other variables, i.e. slope gradient, aspect and hillshade. The measured EC in the surface soil layer showed a low significant correlation with soil and vegetation indices either in winter or in summer. The red and blue bands in the visible spectral bands maintained a superior significant correlation with measured soil salinity in both seasons, which helped in creating the soil adjusted salinity index for soil salinity prediction. This index showed a high correlation with elevation and measured soil EC. These results led us to develop a multiple linear regression model for soil salinity prediction based on elevation and the new index. This developed model is the first one for soil salinity prediction for our study area, with the prediction power of $45 \%$ that can be significantly improved in further studies by using very high resolution satellite images and digital elevation model as well as improving sampling method of soil samples.

\section{Acknowledgements}

We deeply thank Mr. Abdel-Hamid BRADAI and Mr. Djamel-Eddine MOKHTARI at the University of Chlef Algeria for their availability and support. We also thank Dr. Benyoucef GHARBI at the University of Khemis Miliana, Algeria and the staffs at the Institute of Agricultural Environment and Resources, Shanxi Academy of Agricultural Sciences, China for their support and valuable contribution.

\section{References}

Akramkhanov A. 2005. The Spatial Distribution of Soil Salinity: De- tection and Prediction. Ecology and Development Series No. 32. Göttingen: Cuvillier, 120.

Allbed A, Kumar L. 2013. Soil salinity mapping and monitoring in arid and semi-arid regions using remote sensing technology: a review. Advances in Remote Sensing, 2: 373-385.

Allbed A, Kumar L, Sinha P. 2014. Mapping and modelling spatial variation in soil salinity in the Al Hassa Oasis based on remote sensing indicators and regression techniques. Remote Sensing, 6(2): $1137-1157$.

Al-Khaier F. 2003. Soil salinity detection using satellite remote sensing. Msc Thesis. Enschede: International Institute for Geo-Information Science and Earth Observation, 1-70.

Boettinger J L, Ramsey R D, Bodily J M, et al. 2008. Landsat spectral data for digital soil mapping. In: Hartemink A E, McBratney A, de Lourdes Mendonça-Santos M. Digital Soil Mapping with Limited Data. Berlin: Springer, 193-202.

Bouaziz M, Matschullat J, Gloaguen R. 2011. Improved remote sensing detection of soil salinity from a semi-arid climate in Northeast Brazil. Comptes Rendus Geoscience, 34(3): 795-803.

Browing D M, Duniway M C. 2011. Digital soil mapping in the absence of field training data: A case study using terrain attributes and semi-automated soil signature derivation to distinguish ecological potential. Applied and Environmental Soil Science, 2011, 421904, doi: 0.1155/2011/421904.

Chander G, Markham B L, Helder D L. 2009. Summary of current radiometric calibration coefficients for Landsat MSS, TM, ETM+, and EO-1 ALI sensors. Remote Sensing of Environment, 113(5): 893-903.

Chen X, Yan J F, Chen Z, et al. 2009. A spatial geostatistical analysis of impact of land use development on groundwater resources in the Sangong Oasis Region using remote sensing imagery and data. Journal of Arid Land, 1(1): 1-8.

Dehni A, Lounis M. 2012. Remote sensing techniques for salt affected soil mapping: application to the Oran region of Algeria. Procedia Engineering, 33: 188-198.

Douaoui A, Lepinard P. 2010. Remote sensing \& soil salinity: mapping of soil salinity in the Algerian plain "Lower-Cheliff". Geomatics Expert, 76: 36-41. (in French)

Douaoui A, Yahiaoui I. 2015. Using remote sensing, GIS and kriging to improve soil salinity mapping in the Hmadna plain (Algeria). Topraksu-Dergisi Soil-Water Journal, Special Issue: 1-5.

Douaoui A E K, Hervé N, Walter C. 2006. Detecting salinity hazards within a semiarid context by means of combining soil and remote sensing data. Geoderma, 134(1-2): 217-230.

Eldeiry A, Garcia L. 2004. Spatial modeling using remote sensing, GIS, and field data to assess crop yield and soil salinity. Hydrology Days, 7: 55-66.

Farifteh J, van der Meer F, van der Meijde M, et al. 2007. Spectral characteristics of salt affected soils: a laboratory experiment. Geoderma, 145(3-4): 196-206.

Fernández-Buces N, Siebe C, Cramb S, et al. 2006. Mapping soil salinity using a combined spectral response index for bare soil and vegetation: A case study in the former lake Texcoco, Mexico. Journal of Arid Environments, 65: 644-667. 
Finn M P, Reed M D, Yamamoto K H. 2012. A straight forward guide for processing radiance and reflectance for EO-1 ALI, Landsat 5 TM, Landsat $7 \mathrm{ETM}+$, and ASTER. Unpublished Report from Center of Excellence for Geospatial Information Science, United State Geological Survey (USGS). USGS, Rolla, Missouri, USA. [2012-07-24]. http://cegis.usgs.gov/.

Huete A R, Liu H, de Lira G R, et al. 1994. A soil color index to adjust for soil and litter noise in vegetation index imagery of arid regions. Geoscience and Remote Sensing Symposium, 2: 1042-1043.

Khan N M, Rastoskuev V V, Shalina E, et al. 2001. Mapping salt-affected soils using remote sensing indicators-a simple approach with the use of GIS IDRISI. In: Proceedings of the $22^{\text {nd }}$ Asian Conference on Remote Sensing. Singapore: Centre for Remote Imaging, Sensing and Processing (CRISP), 25-29.

Lesch S M, Strauss D J, Rhoades J D. 1995. Spatial prediction of soil salinity using electromagnetic induction techniques: 1. Statistical prediction models: A comparison of multiple linear regression and cokriging. Water Resources Research, 31(2): 373-386.

Manière R, Bassisty E, Celles J C, et al. 1993. The use of spatial remote sensing for land use mapping in arid Mediterranean zones: Case of Ain Oussara (Algeria). Orstome Handbooks: Series of Pedology, 28: 67-80. (in French)

Mehrjardi R T, Mahmoodi Sh, Taze M, et al. 2008. Accuracy assessment of soil salinity map in Yazd-Ardakan Plain, Central Iran, based on Landsat ETM+ imagery. American-Eurasian Journal of Agriculture \& Environmental Sciences, 3(5): 708-712.

Metternicht G I, Zinck J A. 2003. Remote sensing of soil salinization: potentials and constraints. Remote Sensing of Environment, 85: $1-20$.

Mokhtari D E, Douaoui A, Yahiaoui I. 2012. Geomatics use in the evaluation of surface qualities degradation in saline area (The case of the lower Cheliff plain). Energy Procedia, 18: 1557-1572.
Mulder V L, de Bruin S, Schaepman M E, et al. 2011. The use of remote sensing in soil and terrain mapping-A review. Geoderma, 162: 1-19.

Noroozi A A, Homaee M, Farshad A. 2012. Integrated application of remote sensing and spatial statistical models to the identification of soil salinity: A case study from Garmsar Plain, Iran. Environmental Sciences, 9(1): 59-74.

Pearson R L, Miller L D. 1972. Remote mapping of standing crop biomass for estimation of the productivity of the short-grass prairie, Pawnee National Grasslands, Colorado. In: Proceedings of the $8^{\text {th }}$ International Symposium on Remote Sensing of Environment. Michgan: Willow Run Laboratories, Environmental Research Institute of Michigan, Ann Arbor, 1357-1381.

Rouse J W, Haas R H, Schell J A, et al. 1974. Monitoring the vernal advancement of retrogradation (greenwave effect) of natural vegetation. Type III Final Report RSC 1978-4. Remote Sensing Center, Texas A\&M University. College Station, Texas, USA, 1-93.

Shrestha R P. 2006. Relating soil electrical conductivity to remote sensing and other soil properties for assessing soil salinity in northeast Thailand. Land Degradation \& Development, 17(6): 677-689.

Tajgardan T, Ayoubi S, Shataee S, et al. 2010. Soil surface salinity prediction using ASTER Data: Comparing statistical and geostatistical models. Australian Journal of Basic and Applied Sciences, 4(3): 457-467.

Wang F, Chen X, Luo G P, et al. 2013. Detecting soil salinity with arid fraction integrated index and salinity index in feature space using Landsat TM imagery. Journal of Arid Land, 5(3): 340-353.

Wang H, Wang J, Liu G. 2007. Spatial regression analysis on the variation of soil salinity in the Yellow River delta. Proceedings SPIE 6753, Geoinformatics 2007: Geospatial Information Science, 67531U, doi: 10.1117/12.761911. [2007-07-26]. http://dx.doi.org/10.1117/12.761911.

Yahiaoui I, Douaoui A. 2014. Land Use Dynamics in the Lower-Cheliff Plain (Algeria). Verlag: Lambert Academic Publishing, 81. 